though at present incomplete, states that the mean free path for annihilation is in general greater than the range of the positron, so that such annihilation should be evidenced by the appearance of quanta of about half a million electron-volts energy and a very small number of quanta of about one million electron-volts energy when positrons pass through matter ${ }^{20}$. The experiments by Gray and Tarrant $^{18}$ on the scattering of thorium $C^{\prime \prime} \gamma$-rays showed the existence of secondary radiation of such energies, but some of the more recent experiments on the scattering of hard $\gamma$-rays fail to show a secondary radiation which can be attributed to the annihilation of positrons. Our cosmic ray photographs show that in the electron showers there are present large numbers of secondary photons, many of which are in this range of energy, but it is not yet certain if they are produced in part by the annihilation of positrons. In two very recent papers, Joliot ${ }^{21}$ and Thibaud ${ }^{22}$ report the observation in experiments with artificially produced positrons of secondary photons of the energies to be expected if they arise from the annihilation of positrons. By control experi- ments with negative electrons, they showed that a beam of positrons impinging upon matter results in the production of a considerably greater quantity of photons than does an equal number of negative electrons.

1 Anderson, Science, 76, 238 ; 1932.

3 Millikan and Anderson, Phys, Rev, 40, 325; 1932 . See also Anderson, Phys. Rev., 41, 405 ; 1932: and Kunze, Z. Phy8., 80, 559 1933 .

Anderson, Phys. Rev., 43, 491; 1933.

Millikan, Science, 78, 153; 1933.

5 Blackett and Occhialini, Proc. Roy. Soc., A, 139, 699; 1933.

- Chadwick, Blackett and Occhialini, NATURE, 131, 473, April 1, 1933.

Curie and Joliot, C.R., 196, 1105 ; 1933.

Meitner and Philipp, Naturoiss, 21, 286; 1933.

${ }^{\circ}$ Anderson, A.A.A.S. meeting, April 28, 1933, and Science, 77, $32 ; 1933$.

Anderson and Neddermeyer, Phys. Rev., 43, $1034 ; 1933$.

${ }^{11}$ Curie and Joliot, C.R., 196, $1581 ; 1933$.

${ }_{12}$ Meitner and Philipp, Naturwiss., 24, 468; 1933.

${ }^{13}$ Curie and Joliot, C.R., 197, 237; 1933

14 Oppenheimer and Plesset, Phys. Rev., 44, 53; 1933. Beck, $Z$. Phys., 83, 498; 1933

Anderson, Phys. Rev., 44, 406; 1933.

${ }^{16}$ Chao, Proc. Nat. Acad. Sci., 16, 431; 1930. Phys. Rev., 36, $1519 ; 1930$.

17 Meitner and Hupfield, Naturwiss., 19, 775 ; 1931.

${ }_{18}$ Gray and Tarrant, Proc. Roy. Soc., A, 136, 662; 1932.

Anderson, Millikan, Neddermeyer and Pickering, Proc. Nat. Acad. Sci. Autumn meeting Nov. 20, 1933. See also abstract by Anderson and Neddermeyer, A.A.A.S. meeting, Dec. 30, 1933.

${ }^{20}$ Fermi and Uhlenbeck, Phys. Rev., 44, 510; 1933.

${ }^{21}$ Joliot, C.R., 197, 1623 ; 1933.

22 Thibaud, C.R., 197, 1629; 1933.

\title{
Research in the Cotton Industry
}

$\mathrm{I}^{\mathrm{N}}$ a discourse entitled "Industrial Research : A Business Man's View" delivered at the Royal Institution on December 15, Sir Kenneth Lee made some striking references to the place of research in industry, based largely on the actual experience of Messrs. Tootal Broadhurst Lee and Co., Ltd. Up to twenty-four years ago, they had no scientific staff connected with the business, and it was only experience gained during the War which induced them to make a direct attack by means of research on the production of cotton material like wool in its power to resist and recover from creasing. Sir Kenneth proceeded to outline briefly the steps which after fourteen years' work had enabled them to market successfully a creaseless cotton fabric.

The initial step was the assembling of the nucleus of a research staff in the belief that, even in such an old-established industry as that of cotton, research could be of immense advantage; systematic work on the chemical and physical properties of cotton or on the physical basis of the machine processes to which it was subjected in the course of manufacture should greatly facilitate uniform and steady progress. Alluding to the lack of such systematic work in the cotton industry, Sir Kenneth cited the process of mercerisation. Although Mercer discovered in 1844 that caustic soda had a marked action on cotton, it was nearly fifty years later when Lowe discovered how the conditions must be modified to produce lustre by mercerisation, while Mercer's discovery itself did not attract the active interest of academic scientific workers.

In its progress from the bale, through spinning, weaving, bleaching, dyeing and finishing, cotton is subjected to various physical and chemical pro- cesses. It was therefore decided, when the Research Department was formed, that the staff should consist of chemists and physicists who should work together on the problems involved, and when a laboratory solution had been found, should share their knowledge with technical men in an endeavour to harvest their results in manufacture. This was the first time that chemists and physicists had been engaged in co-operation in the cotton industry. It was also decided that lack of experience in dealing with cotton should be no bar to the engagement of any member of the staff. Provided ability to conduct research was evident, this lack of experience was even regarded as an advantage, since such workers would not have got into ruts and would be more likely to contribute a fresh outlook on the problem.

In addition to the decision to adopt a definite research objective, the further important initial decision was made to carry out routine testing by a separate staff, housed in the same laboratory, so as to provide the maximum contact between the research staff and the analytical or testing staff. The wisdom of the policy embodied in these preliminary decisions is attested not only by the results achieved by the Tootal Broadhurst Lee Co., Ltd., but also by the experience of numerous other industrial research organisations in Great Britain and in other countries.

Most of the published work on cotton had previously been concerned with large-scale experiments on yarns and fabrics. In view of the dependence of the physical behaviour of such materials not only on the yarn comprising them but also on the weave, on the twist and diameter of the yarns and the nature of the innumerable 
cotton hairs, it was decided to commence by investigating the properties of the cotton hairs themselves, the fine fibres about an inch long and a few ten-thousandths of an inch in diameter from which all cotton yarns are made. Special apparatus was devised to compare the elastic properties of the various textile fibres in air and in various liquids, and the sponginess of the hairs proved to be of great importance.

It was early realised that there are at least two methods of attacking the creasing problem. One is to fill the spongy cotton hairs with some elastic substance: another is to combine with the cotton some substances which would eliminate its plastic nature and give it the necessary resilience. Both methods were tried and finally the introduction of synthetic resins into the fibre proved successful, though only after some years of work had shown the way to retain all the other textile qualities of cotton when it was impregnated with resin. To be suitable for this purpose, the synthetic resin molecules should be small during the impregnation of the fabric so as to enter the cotton hairs. The substances used must not damage the fabric nor must resinification by heat or otherwise be effected under conditions which damage the fabric. Furthermore, the resin must be colourless and not discoloured by strong sunlight; it must be elastic so as to give the anti-creasing properties, and must be introduced without impairing the suppleness of the fabric. It must also withstand laundry treatment.

These conditions considerably limited the types of resin which could be used. Further investigation showed that when the resin was mainly inside the cotton hairs a soft fabric was obtained, but when a considerable amount of resin was left between the hairs and the yarns, the cloth was hard and stiff. The microscopic examination also showed that the diameter of the cotton hairs is permanently increased, causing the fabric to give better cover, and the treatment accordingly must be directed towards getting rid of all the resin between the fibres. By treating cotton and rayon fabrics in this way, effecting final condensation after the resin solution was put on the cloth, remarkable anticreasing properties were conferred. In addition, shrinkage by washing was reduced while the strength of rayon was increased by 30 per cent when dry and up to 100 per cent when wet.

The next stage of development, from the laboratory to a manufacturing scale, proved difficult as well as costly. In addition to mechanical difficulties, physical and chemical methods of control at each stage of the process had to be elaborated. Not merely the design of suitable machinery, but also the development of suitable testing methods for accurate control made demands on a combination of engineering, chemical and physical knowledge which the man with a general training was often better able to meet than a highly specialised research worker.

One of the major difficulties was concerned with an apparatus for converting the resin inside the cotton hair into insoluble form. This had to be done by running a continuous length of cloth through a machine capable of heating it evenly over its width for a short time to a high temperature. Finally an electrical method was selected, which was novel in the electrical trade, and with this machine a production of some thousands of yards sufficed to gain the experience for the design of full scale plant in which weakness of design and lack of robustness in various details were eliminated.

Discussing the successful conclusion of this research directed to a definite objective, Sir Kenneth Lee raised the question as to how much stronger our industrial position might be as a result of more well-directed research. Patents themselves indicate the extent to which our research activity is overshadowed by that of competitive countries. Even most of our newer industries are handicapped by paying heavy tribute to foreign countries in the forms of licences, and from the results achieved by his own company Sir Kenneth said that they would be glad to see other industries, particularly the older industries, pursuing the same policy to a much greater extent. $\mathrm{He}$ considers that the present time is opportune for a great increase in the amount of scientific research in industry, and reduced expenditure on research in other countries offers us a correspondingly greater chance of taking the lead. Researches directed to putting manufacture on a sound scientific basis would undoubtedly repay the expenditure of time, money and patience involved, and the nations doing the most intelligent research work are likely in the long run to have the greatest chance of prosperity. We have in Great Britain the necessary ability for fundamental research if only the business community would supply sufficient funds, and Sir Kenneth urged that there is no wiser expenditure for an industrial undertaking than the provision of funds for research.

\section{$\mathrm{Ob}$ it uary}

DR. D. H. Scotr, F.R.S.

WORKERS in the fields of natural knowledge are often described as pioneers in the development of novel views, as men whose enthusiasm was stirred in early life by the preaching of a new doctrine. Dukinfield Henry Scott's early days coincided with an intellectual revolu- tion. He was born on November 28, 1854, a few years before the publication of the "Origin of Species", and graduated from Christ Church in 1876 at a time when men were under the influence of a new gospel. He died on January 29, 1934.

Following the example of other young men of 